
8
Research Square
Preprints are preliminary reports that have not undergone peer review.
They should not be considered conclusive, used to inform clinical practice, or referenced by the media as validated information.

\title{
The Influence of Illness Perception, Anxiety and Depression Disorders on Students Mental Health during COVID-19 Outbreak in Pakistan: A Web- Based Cross-Sectional Survey
}

\section{Muhammad Aqeel ( $\sim$ Aqeel.1924@gmail.com)}

Foundation University, Department of Psychology, Defense Avenue, Phase-I, D.H.A., Islamabad

Kanwar Hamza Shuja

Quaid-i-Azam University

Jaffar Abbas

Shanghai Jiao Tong University

Tasnim Rehna

National University of Modern Languages

Arash Ziapour

Kerman Shah University of Medical Sciences

\section{Research article}

Keywords: Mental health, Coronavirus-disease (COVID-19), Anxiety disorder, Illness perception, Depressive disorder

Posted Date: June 1st, 2020

DOI: https://doi.org/10.21203/rs.3.rs-30128/v1

License: (c) (i) This work is licensed under a Creative Commons Attribution 4.0 International License.

Read Full License

Version of Record: A version of this preprint was published at International Journal of Human Rights in Healthcare on August 20th, 2021. See the published version at https://doi.org/10.1108/IJHRH-10-20200095. 


\section{Abstract}

Background: Since the emergence of a coronavirus disease (2019-nCoV) in December 2019, the whole world is in a state of chaos. Isolation strategy with quarantine is a useful model in controlling transmission and rapid spread. As a result, people remained at homes and disrupted their outside daily activities. It led to the closure of educational institutes, which is a source of many students to cope with numerous personal and familial issues. This study focuses on exploring the relationships and potential mediational pathways between mental health problems, illness perception, anxiety, and depression disorders.

Method: The study incorporated snowball sampling techniques through a cross-sectional, web-based survey and recruited 500 students from different public and private universities from twin cities, Rawalpindi, and Islamabad from March 23 to April 15, 2020, during the coronavirus outbreak lockdown. The study used four instruments, Beck Depression Scale, Beck Anxiety Inventory, Revised Illness Perception Questionnaire, and The Warwick-Edinburgh Mental Well-being Scale for assessing depression, anxiety, illness perception, and mental health disorders.

Results: The findings indicated normal (43.2\%) mild (20.5\%), moderate (13.6\%), and severe $(22.7 \%)$ level of anxiety prevalence in students. Results specified a normal (65.9\%), mild (9.10\%), moderate $(9.12 \%)$, and severe (15.90\%) depression prevalence, and findings stipulated that anxiety disorder prevalence was higher than the depression disorder. The correlational results specified a negative and significant relationship between mental health, illness perception, anxiety, and depression symptoms. The multiple regression analysis stated that anxiety and depression disorders mediated the relationship between mental health and present illness perception. The perception of illness exhibited a relation to depression and anxiety disorders.

Conclusion: The study proposed a model to address mental health problems during the lockdown. The (2019-nCoV) illness perception developed mental disorders, including anxiety and depression, which has declined individuals' mental health. There is an urgent need for ongoing clinical examination and management to address psychological disorders, and findings suggest assessing mental health to combatting the pandemic worldwide. Findings recommend developing strategies to promote mental healthcare facilities during COVID-19 wide-ranging disasters. These results highlight the impending importance of devising strategies to treat mental health problems.

\section{Background}

World Health Organization announced the coronavirus illness 2019 (COVID-19) epidemic, resulted in severe Acute Respiratory Syndrome (SARS) in 2003, designated an epidemic from March 12, 2020[1, 2]. The U.N. Educational, Scientific, and Cultural Organization anticipated that one hundred seven states around the world had executed state school closures linked to COVID-19outbreak On March 18, 2020, influencing 862 million kids and adolescent people, approximately half the worldwide student populace. 
This critical condition had quickly raised from twenty-nine states with countrywide schools, colleges, or university closures before a week[3]. The decision to close schools was in line with the logic of supporting evidence and assumptions related to the epidemic, such as it would minimize social interaction between children, which helps prevent transmission[4-6]. The phenomenon of social distancing brought on by the coronavirus disease (COVID-19) pandemic has caused severe disruption of the daily lives of many people around the globe[7, 8]. According to UNESCO, all the numerous countries have postponed educational activities at educational institutes internationally, as of April 8, 2020, in around 188 countries $[3,7,9]$. Approximately 1-5 million students (90\%), all over the world are currently out of education[3].

Director-General of UNESCO shared his concerns by stating, "The global scale and speed of the current educational disruption are unparalleled" $[10,11]$. This sudden closure of educational institutes and disruption of the daily routine for children with mental health needs are dire, as this can lead to a lack of resources that they acquire through their educational activities and their respective institutes in routine life[10-12]. Children affected by educational institute closure may also miss the sense of normalcy and stability they have in their institutes [13]. Young Minds, a mental health charity based in the U.K, in a recently conducted survey on a sample of 2111 children with mental illness with age up to 25 . They reported that around $26 \%$ of children stated that they could not access mental health supports like faceto-face services and peer, support groups, as such service is postponed. Telephonic or online supports are challenging for many of them. Additionally, around $83 \%$ of the students stated in that survey that the lockdown due to pandemic had worsened their conditions[14].

Routine activities and scholarly sources are a way of coping for many students with mental health issues, as well as for those students who do not have mental health issues[15-17]. Educational institutes help students to elevate from whatever problems they are facing in their personal life by connecting with other students and teachers[18-21]. In a more refined sense, educational institutes act as an anchor in the lives of many of the students, and with the institutes closed, they have lost their anchor[22, 23]. It could potentially trigger their symptoms and lead them to relapse or the formation of newer mental health issues[24, 25]. Chiu (2020), a clinical psychologist, stated that for many students who have mental health issues (anxiety and depression), going to school is a struggle. However, the institutes provided students with a routine to which they could stick with. Accordingly, this can lead students with worldwide depression or anxiety in a lot of difficulties once the institutes are resumed again[7]. The past literature specified that many scholars had conducted such kinds of research on a similar subject, and the most prevalent form of mental health issues found in students was that of stress, anxiety, and depression [15, 25-27].

Similar, reports about the elevated level of stress and anxiety have shown that students around the globe have reported health issues [28-31]. In a recent poll conducted by a student-counseling group in Hong Kong, after the cancellation of university exams, approximately $20 \%$ of the students reported a maximum level of stress on a scale of 10[7,31-33]. Students, along with the disruption of their routine lives, are also facing the uncertainty and fear to receive infection by the coronavirus, making staying healthy as another stressor for students 
$[34,35]$. Furthermore, several students are also facing issues like delay in their degrees, loss of part-time jobs, the prospect of employment in such circumstances [4]. Likewise, social distancing can also lead to potential social isolation for those students with broken families or abusive households [36, 37]. Thus, with miserable economic conditions and uncertainty, frustration in families can even further escalate the abuse in already abusive families towards children[11, 38-40]. In China, people have reported child abuse, exploitation, neglect, and domestic violence more than three times during the lockdown in China[41-43]. Similar reports also hiked during the last public health emergency caused by Ebola during 2014-16[25, 44].

The present study focuses on assessing the mental health issues that may form the Pakistani student population during the current lockdown. As currently, there are not many known facts about the long-term mental health issues in children and adolescents after such a global scale pandemic. Though there are researches on the affected patients and health service providers, mental health during and after the outbreak of Severe Acute Respiratory Syndrome (SARS) in 2006[45-47], researches on the mental health of ordinary citizens and students during and after it are not many. Especially in the case of students, the reported shreds of evidence were insufficient, making it an essential gap for researchers in this time of need.

For this reason, the current research aimed at exploring the mental health of students who are currently at homes due to the COVID-19 pandemic. Since, in comparison to SARS, the current COVID-19 epidemic is on a much larger scale. As it continues, the economic instability, frustration, and fear among the masses increase along with it $[1,12,48,49]$. As for students' difficulties, such as uncertainty, anxiety about the future and health, isolation from peers will also increase. The parents who already have mental health or family relationship problems are in a very vulnerable state. They need timely support at this time of crisis. Such assistance should not only be temporary. The mental health problems would last over the long term, and there is a need for conducting further studies to examine the impact of the prolonged closure of educational institutions. By practicing, the isolation that is more social increases the extreme fear of mental health, and wellbeing in students, which is the leading deplorable cause of the pandemic[50].

\section{Method}

\section{Objectives}

Objective 1:

To examine the prevalence of anxiety and depression disorders in students during COVID-19 lockdown.

\section{Objective 1:}

To examine the mediating role of depression and anxiety disorders symptoms in the relationship between illness perception and mental health in Pakistan's students during the COVID-19 outbreak 
lockdown.

\section{Hypotheses}

H 1:

Illness perception is positively associated with anxiety and depression disorders symptoms in Pakistani students during the COVID-19 outbreak lockdown.

\section{H 2:}

Anxiety and depression disorders symptoms are negatively associated with mental health among Pakistani students during the COVID-19 outbreak lockdown.

\section{Research design}

The study combined a snowball sampling technique with a cross-sectional, web-based survey and recruited 500 students from different public and private universities from twin cities, Rawalpindi, and Islamabad from March 23 to April 15, 2020, during the coronavirus outbreak lockdown. This research used a survey method to examine the preventing and suppression policy about severe acute respiratory syndrome coronavirus 2 (SARS-CoV-2) through contact or droplet. This study carried out a web-based cross-sectional survey during the COVID-19lockdown from different universities' official internet platforms, including WhatsApp and Facebook. It was helpful because most of Pakistan's students use online social media services like WhatsApp, Facebook. For promoting and recruiting the participation of possible samples, all students in the present study would get a report after completing this examination of their mental health. These online questionnaires were voluntary, and natures were non-commercial.

\section{Sample and Procedure}

The study recruited five hundred participants from different public and private universities of twin cities, Rawalpindi and Islamabad, Pakistan, from March 23 to April 15, 2020, during COVID-19 lockdown. Age ranged between 16 to 25 years $(M=20.31, S D=1.51)$. This present research was conducted in accordance with the ethical guidelines of the American Psychological Association. The Research Ethics Committee also approved it of Shanghai Jiao Tong University (SJTU), China. We approached the participants through online self-reported measures and uploaded on different University official groups, and an online survey platform to gather survey data. The inclusion criteria used for the study included: 1) this study has enrolled only students of the B.S. classes; 2 ). They were off from their respective Universities due to lockdown because of the COVID-19 outbreak. Those students who fulfilled the selection, as mentioned earlier, the study selected the criteria related to the part of the online survey. We excluded the participants who failed to meet the selection criteria of the survey. All students voluntarily contributed and accepted the electronic, written informed consent for their participation in the present online survey. The sampling technique applied was snowball sampling, and this study identified students 
through their demographic information, which included their region, gender, age, marital status, education level, and grades.

\section{Measures}

The survey questionnaire included two parts: (1) necessary demographic information, (2) mental health assessment.

\section{Demographic Information}

Demographic information comprised of the region, age (years), gender (male or female) marital status (married, unmarried, or divorced), education level, and grades

\section{Mental Health Assessment}

This study used four instruments to measure the mental health status of students during the COVID-19 lockdown. This incorporated four standardized instruments in the present research to examine the illness perception, (Cognitive perceptions including the effect on the life duration of illness, Beliefs about the effectiveness of treatment, control over disease, and experience of symptoms), Anxiety disorder, Depression disorder, and Mental Health.

\section{The Beck Depression Scale}

TheBeck Depression Scale(BDI-II; Dozois, 2010) is a 21-item self-reporting instrument, which is useful for assessing the severity of depression in the psychiatric and healthy population. Each item of BDI-II is scored on a four-point Likert scale from 0 (symptom absent) to 3 (severe symptoms). The sum of BDI-II scores classification is as follows: Normal depression (0-13), mild depression (14-19), moderate depression (20-28), or severe depression (29-63). The I.P.Q.- R has illustrated adequate reliability and validity[51]. In the current study, the Cronbach alphas (a) is 0.91 which indicated sufficient reliability.

\section{The Beck Anxiety Inventory-BAI}

The Beck Anxiety Inventory (BAl; Beck, Epstein, Brown, \& Steer, 1988) is a 21-item self-reporting instrument, which is useful for evaluating the severity of anxiety in the psychiatric and healthy population. Each item of BAI score shows on a four-point Likert scale from O (Not at all) to 3 (Severely - it bothered me a lot). The sum of BAl scores classification is as follows: minimal/low anxiety ( $0-7)$, mild anxiety (8-15) moderate anxiety (16-25), or severe anxiety (26 or 63 ). The BAI has illustrated adequate reliability and validity[52]. In the current study, the Cronbach alphas(a) is 0.93 , which indicated sufficient reliability.

\section{The RevisedIIIness Perception Questionnaire-IPQ}

The Revised Illness Perception Questionnaire (I.P.Q.; Moss-Morris et al., 2002) was used to measure cognitive representations of illness of students(Moss-Morris et al., 2002). It also assesses an individual's 
feelings and beliefs about their disease. It comprises of five subscales: Cognitive perceptions including the effect on the life duration of illness, Beliefs about the effectiveness of treatment, control over sickness, and experience of symptoms. The I.P.Q.- R has illustrated adequate reliability and validity[53].In the current study, the Cronbach alphas(a) is 0.95 , which indicated sufficient reliability.

\section{The Warwick-Edinburgh Mental Well-being Scale-WEMW}

The Warwick-Edinburgh Mental Well-being Scale (WEMW; Stewart-Brown, \&Jan Mohamed, 2008) is an a14-item self-reporting scale helps evaluate the mental wellbeing in a normal or clinical population. Each item of WEMW indicates scores on a five-point Likert scale from 1 (None of the time) to 5(All of the time). The WEMW has illustrated adequate reliability and validity [54]. In the current study, the Cronbach alphas (a) is 0.91 , which indicated sufficient reliability.

\section{Analysis plan}

First, missing values of the revised illness perception questionnaire, beck anxiety inventory, beck depression inventory, the Warwick Edinburgh mental wellbeing scale dealt through an imputation technique on Spss-23 (Field, 2017). The study also performed descriptive analyses to determine the prevalence of anxiety and depression disorders in the sample. Second, this study applied the productmoment correlation analysis to check the association between anxiety, depression, mental health, and illness perception(Field, 2017). Third, mediation analysis performed to analyze potential mediation pathways in anxiety, depression, mental health, and understanding of disease (Baron \& Kenny, 1986). Mediation analysis also delivered to evaluate the mediating role of psychiatric features as anxiety or depression in the relationship between illness perception and mental health in Pakistan's students during the COVID-19 outbreak lockdown via the Statistical Software of Structural equation modeling (S.E.M.-23) [55].

\section{Results}

Table 1. Correlation matrix, mean and standard deviation, alpha Cronbach coefficient of perception of illness, anxiety, and depression disorder in Pakistan's students during COVID-19 outbreak lockdown $(\mathrm{N}=500)$ 


\begin{tabular}{|c|c|c|c|c|c|c|c|c|c|c|c|}
\hline Variables & M & SD & A & 1 & 2 & 3 & 4 & 5 & 6 & 7 & 8 \\
\hline 1.BAI & 14.20 & 13.00 & .91 & - & $.70^{\star \star}$ & $.48^{\star \star}$ & $.62^{\star \star}$ & $.59^{\star \star}$ & $.38^{\star \star}$ & .28 & -.29 \\
\hline 2.BDI & 14.36 & 12.42 & .93 & & - & $.44^{\star \star}$ & $.50^{\star \star}$ & $.55^{\star \star}$ & $.32^{*}$ & .26 & $-.48^{\star \star}$ \\
\hline 3.PI & 102.6 & 35.76 & .95 & & & - & $.49^{\star *}$ & $.53^{\star \star}$ & $.94^{\star *}$ & $.85^{\star \star}$ & -.24 \\
\hline 4.EPI & 3.00 & 3.76 & .90 & & & & - & $.96^{\star \star}$ & $.31^{*}$ & .25 & -.29 \\
\hline 5.ECl & 2.88 & 3.75 & .90 & & & & & - & $.34^{*}$ & .26 & $-.32^{\star}$ \\
\hline 6.CV & 67.13 & 21.44 & .93 & & & & & & - & $.68^{* *}$ & -.28 \\
\hline 7.Pc & 30.68 & 13.13 & .90 & & & & & & & - & -.04 \\
\hline 8.Mental Health & 48.45 & 10.12 & .91 & & & & & & & & - \\
\hline
\end{tabular}

Note. $\mathrm{BAI}=$ Beck Anxiety Inventory; $\mathrm{BDI}=$ Beck Depression Inventory; $\mathrm{PI}=$ Overall Perception of IIIness; $\mathrm{EPI}=$ experience of symptoms is related to the perception of past illness. E.C. I= Experience of symptoms is associated with the perception of current illness; $C V=$ Cognitive perceptions including the effect on the life duration of illness; PA= Possible causes of illness

The Cronbach alpha reliability of perception of illness, along with their subscales, Beck Depression Inventory, and the Beck Anxiety Inventory, have adequately presented this study. As described in Table 1, the findings demonstrated that depression disorder symptoms indicated positive and significant linkage to anxiety disorders symptoms and illness perception along with the subscales experience of symptoms. The problems are related to the understanding of past or present illness and Cognitive perceptions, including the effect on the life duration of disease. Still, it is negatively associated with mental health in Pakistani students' samples during COVID-19 lockdown. Furthermore, the study's findings illustrated that anxiety disorder symptoms positively significantly associated with illness perception along with their subscales as the experience of symptoms is related to the perception of past or present illness and Cognitive perceptions, including the effect on the life duration of illness. Still, it is negatively associated with mental health in Pakistani students during the lockdown. Besides, the results of the present study indicated that mental health was negatively significantly associated with illness perception along with their subscales. The experience of symptoms is related to the perception of past or present illness and cognitive impressions, including the effect on the life duration of disease in Pakistani students during the COVID-19 lockdown.

Table 2. Multiple mediating roles of depression and anxiety disorders symptoms in the relationship between illness perception and mental health in Pakistani students during COVID-19 outbreak lockdown $(\mathrm{N}=500)$ 


\begin{tabular}{llllllllll} 
Sr. & BAI & \multicolumn{9}{c}{ BDI } & \multicolumn{5}{c}{ Mental Health } \\
\hline Variables & $\boldsymbol{B}$ & SE & $\boldsymbol{B}$ & $\boldsymbol{B}$ & SE & $\boldsymbol{\beta}$ & $\boldsymbol{B}$ & S.E. & $\boldsymbol{\beta}$ \\
\hline EPI & 2.20 & .43 & $.62^{\star \star \star}$ & -3.24 & 1.290 & $-.95^{\star \star}$ & & & \\
\hline ECl & & & & 3.60 & 1.222 & $1.08^{\star \star}$ & & & \\
\hline BAI & & & & .616 & .120 & $.64^{\star \star \star}$ & & & \\
\hline B.D.I. & & & & & & & -.38 & .109 & $-.48^{\star \star \star}$
\end{tabular}

Note. $\mathrm{BAI}=\mathrm{Beck}$ Anxiety Inventory; $\mathrm{BDI}=$ Beck Depression Inventory; $\mathrm{PI}=$ Overall Perception of IIIness; $\mathrm{EPI}=$ experience of symptoms is related to the perception of past illness; E.C. I= Experience of symptoms is associated with the perception of current illness.

Table 2 Illustrates the results for the model evaluating the mediating role of depression and anxiety disorders symptoms in the relationship between illness perception and mental health in Pakistanistudent's sample during the lockdown. This study's findings found that the model fit sufficiently; $\chi^{2}(4)=.796, p<.939, \chi^{2} / d f=.199$, RMSEA $=.000(.00, .52), \mathrm{CFI}=1.00, \mathrm{NFI}=.98, \mathrm{IFI}=1.01, \mathrm{RFI}=$ $.99, \mathrm{TLI}=1.05$. This study's results revealed the experience of symptoms is related to the perception of current illness (EPI)was significantly predicted anxiety disorders symptoms $(B A I)(\beta=.62, p<.000)$ and depression disorders symptoms (B.D.I.) among Pakistani student's sample. Moreover, the experience of symptoms is related to the perception of past illness (EPI) was significantly positively predicted depression disorders symptoms (B.D.I.) $(\beta=1.08, p<.01)$ among students. Besides, the study's findings demonstrated that anxiety disorders symptoms in Pakistani students predicted depression disorders symptoms (B.D.I.).

Additionally, this finding revealed that depression disorders symptoms were significantly negatively predicted the mental health of Pakistani students during the lockdown. These afore mention results illustrated those psychological disorders like anxiety and depression fully mediated in the relationship of perception about the past or current illness with mental health in students during COVID-19, lockdown. In simple words, current and present illness perception is associated with a lower level of mental health because it favors of higher prevalence of depression and anxiety disorders in students during the COVID19 outbreak lockdown.

Table 3. Prevalence of psychiatric disorders in students during COVID-19 outbreak lockdown $(N=500)$ 


\begin{tabular}{lll} 
Intensity of disorders & Anxiety disorder & Depression disorder \\
\hline Normal & $43.20(\%)$ & $65.90(\%)$ \\
\hline Mild & $20.50(\%)$ & $s 9.10(\%)$ \\
\hline Moderate & $13.60(\%)$ & $9.10(\%)$ \\
\hline Severe & $22.70(\%)$ & $15.90(\%)$
\end{tabular}

Note. Table 3 shows the levels of anxiety disorder and depressive disorder in Pakistani students

Table 3 reveals that the prevalence of anxiety and depression disorders in students during the COVID-19 outbreak lockdown. The prevalence of normal, mild, moderate, and severe levels of anxiety was $43.2 \%$, $20.5 \%, 13.6 \%$, and 22.7, respectively, among Pakistani students. Likewise, the prevalence of normal, mild, moderate, and severe levels of depression was $65.9 \%, 9.1 \%, 9.1 \%$, and 15.9 , respectively, in the current study sample. The results indicated that the prevalence of anxiety disorder was higher as compared to depression disorder in Pakistani students during the COVID-19 outbreak lockdown.

\section{Discussion}

In recent times, scholars have debated on the adverse effects of the outbreak of the infectious disease (COVD-19) worldwide. There is a more significant discussion across the academic researchers on the linkage between mental health issues and the COVID-19 epidemic. Several previous investigations have suggested that mental health issues have shown a rapid increase in students during the COVID-19 epidemic lockdown[3, 4, 8]. Besides, a few studies have proposed that psychological problems, including anxiety, depression, mood swings, PTSD, have shown increased mental health issues in students because of the exposure to the COVID-19 epidemic [34,56,57]. The present study focused on assessing the effects on the mental health of Pakistani students during the lockdown. As previously discussed, educational institutes act as a source of coping for students with their mental health issues. The study evaluated the potential mediation pathways of depression and anxiety disorders symptoms in the relationship between illness perception and mental health. The study examined the association of mental health with anxiety, depression, and illness perception in Pakistani students sample during the current lockdown. Besides, the study emphasized to define the prevalence of anxiety and depression disorders. The present results revealed that mental health was negatively significantly related to anxiety, depression, and illness perception along with their subscales in Pakistan' students during COVID-19 lockdown. Further, the study showed that illness perception was positively associated with anxiety and depression disordered. These findings are in line with the first and second hypotheses of the current study.

Furthermore, the findings demonstrated that anxiety and depression disorders fully mediated the relationship between illness perceptions with mental health in a student's samples. In simple words, 
illness perception is associated with a lower level of mental health because of its higher level of association with depression and anxiety disorders in students during the COVID-19 lockdown. The current results clarified and supported our second study objective. Moreover, the present study revealed the prevalence of anxiety and depression disorder in students. The current results support the first study objective. These above findings are in line with the findings of similar prior investigations $[1,4,8,29,30$, $46,50,58]$.

Our web-based cross-sectional study indicated a high prevalence of anxiety and depression disorder in the Pakistani student's sample during the current lockdown due to the COVID-19 outbreak. The finding demonstrated that the chances of experiencing anxiety symptoms were more in comparison to depression disorder symptoms. The study results clarified and provided empirical support for precisely comprehending the source of panic in students' samples of Pakistan duringCOVID-19 lockdown. Although, the Pakistan government has already taken several better national actions at critical times to avoid further escalate of the coronavirus disease 2019 (COVID-19) outbreak. There remains a scarcity of related studies on the targeted prevention or intervention to overcome the mental health problems of students and the public during the (COVID-19) outbreak lockdown in Pakistan. This present study has filled the identified mention research gaps by examining the prevalence of psychiatric disorders. Besides, further studies with potential factors can provide interesting findings to provide contributions related to preventing measures for decreasing mental health problems in Pakistani students during the COVID-19 lockdown.

\section{Implementation of the Study}

There are many fair uses and implementations of the current study. Firstly, the study provides empirical evidence to the formation of mental health issues in students as a direct consequence of the current lockdown. Universities should implement and devise strategies to support student's mental health issues through online counseling and other policies. Secondly, students or young people should be involved to spread awareness about the COVID-19 epidemic through proper university channels. Therefore, providing them with a routine and a source to focus and work attentively. Universities and educational institutes should train them to handle the critical situation at this crucial time[59,60]. Thirdly, parents and teachers should provide them with daily routine work to stimulate their minds, which could lead to a reduction in psychological problems $[12,58]$.

\section{Limitation}

There are always some limitations linked to each research study. Similarly, this present research study has also specified some limitations. First, the findings of afore mention study were extracted from the web-based cross-sectional method. It is complicated to draw causal inferences using this design. Second, this study comprised the populace from different universities of two twin cities, Rawalpindi or Islamabad of Pakistan. Therefore, the findings of this study are not generalizable to the entire Pakistani students' community. In the future, the qualitative and interventional study may be useful to explain and comprehend the corvid-19 epidemic's mechanism in prolongation of mental health issues in gender, 
education, age in depth. Third, the current investigation was limited or fixed toCOVID-19 outbreak lockdown. It applied the web-based survey design to prevent potential infections. However, this study obtained the sample data through voluntary participants by using the online system to record the feedback.

Consequently, there is a possibility of the occurrence of selection bias due to web-bases surveys. Third, this study has not initially screened out participants to investigate an individual's mental health problems before lockdown because of the sudden occurrence of this contagious disease in Pakistan. Lastly, the study only has student samples. Still, other samples like working occupational people, laborers, health professionals, and different samples can help under investigations in the future to check the presence of mental health issues in them due to lockdown.

\section{Conclusion}

This study recommended that the present critical situation due to the COVID-19 epidemic could lead to possible mental health issues in Pakistani students. This study also found the prevalence of anxiety and depression disorder in students. It also found that perception, illness, anxiety, or depression disorders were associated with lower levels of mental health of students. Moreover, findings of the study revealed that illness perception was associated with a lower level of mental health, whereas with a higher level of depression and anxiety disorders in students during the COVID-19 outbreak lockdown. This study also suggested that young students who had exposure to the COVID-19 epidemic are more vulnerable to predispose of mental health issues.

\section{Abbreviations}

K.P.K.: Khyber Pakhtunkhwa

N.I.H.: National Institute of Health

2019-nCoV: 2019 novel coronavirus

PTSD: Post-traumatic stress disorder

O.C.D.: Obsessive-compulsive disorder

H.I.V.: Human immunodeficiency virus

COVID-19: Coronavirus disease 2019

WHO: The World Health Organization

SARS: Severe acute respiratory syndrome

MERS: The Middle East respiratory syndrome 
SARS-CoV-2: Severe acute respiratory syndrome coronavirus 2

DSM-5: Diagnostic and Statistical Manual of Mental Disorders, Fifth Edition

H1N1: Influenza A virus subtype (A/H1N1), The subtype of Influenza A virus

\section{Declarations}

\section{Ethics approval and consent to participate}

\section{Ethics and consent to participate}

This present research was conducted in accordance with the ethical guidelines of the American Psychological Association. The Research Ethics Committee of Shanghai Jiao Tong University (SJTU), China also approved the study. The authors obtained the written informed consent from volunteer study's participants

\section{Consent for publication}

Consent approved by the authors

\section{Availability of data and materials}

Yes.

\section{Conflict Interest}

No

\section{Competing Interests:}

The authors are well informed and declared no competing interests.

\section{Funding:}

Shanghai Jiao Tong University (SJTU) has approved this research study. We have not received any funding to execute this research study, the rigorous procedure of collecting data, and other associated processes to conduct this study.

\section{Authors' contribution}

M.A. conceptualized the idea, contributed to study design, completed the entire article, including introduction, literature, discussion, and conclusion. M.A. edited the original manuscript before submission. 
J.A. conceptualized the idea, contributed to study design, completed the entire article, including introduction, literature, discussion, and conclusion. J.A. edited the original manuscript before submission.

K.H.S. contributed to literature and data collection procedures. Hamza supported in analysis and literature investigation.

T.R. contributed to literature and data collection procedures. Hamza supported in analysis and literature investigation.

1. Z. Contributed to rewrite the whole manuscript draft and approved the revised version before submission.

\section{All authors have read and approved the manuscript.}

\section{Acknowledgments:}

Special thanks to professional editing language services to make sure that English grammar is errors free for this manuscript.

\section{References}

1. Tian, F., et al., Psychological symptoms of ordinary Chinese citizens based on SCL-90 during the level I emergency response to COVID-19. Psychiatry Research, 2020. 288: p. 112992.

2. Organization, W.H., COVID-19, and violence against women: what the health sector/system can do, April 7, 2020. 2020, World Health Organization.

3. Viner, R.M., et al., School closure and management practices during coronavirus outbreaks including COVID-19: a rapid systematic review. Lancet Child Adolesc Health, 2020. 4(5): p. 397-404.

4. Huang, Y. and N. Zhao, Generalized anxiety disorder, depressive symptoms, and sleep quality during the COVID-19 outbreak in China: a web-based cross-sectional survey. Psychiatry Research, 2020. 288 : p. 112954.

5. Jackson, C., E. Vynnycky, and P. Mangtani, The Relationship Between School Holidays and Transmission of Influenza in England and Wales. Am J Epidemiol, 2016. 184(9): p. 644-651.

6. Viner, R.M., et al., School closure and management practices during coronavirus outbreaks including COVID-19: a rapid systematic review. The Lancet Child \& Adolescent Health, 2020. 4(5): p. 397-404.

7. Lee, J., Mental health effects of school closures during COVID-19. The Lancet Child \& Adolescent Health, 2020.

8. Zhang, Y., et al., The impact of social distancing and epicenter lockdown on the COVID-19 epidemic in mainland China: A data-driven SEIQR model study. medRxiv, 2020: p. 2020.03.04.20031187.

9. Boursicot, K., et al., Conducting a high-stakes OSCE in a COVID-19 environment. MedEdPublish, 2020. 9. 
10. Bayham, J. and E.P. Fenichel, Impact of school closures for COVID-19 on the U.S. healthcare workforce and net mortality: a modeling study. The Lancet Public Health, 2020. 5(5): p. e271-e278.

11. Van Lancker, W., and Z. Parolin, COVID-19, school closures, and child poverty: a social crisis in the making. The Lancet Public Health, 2020. 5(5): p. e243-e244.

12. Armitage, R. and L.B. Nellums, Considering inequalities in the school closure response to COVID-19. Lancet Glob Health, 2020. 8(5): p. e644.

13. Amon, J.J., COVID-19, and detention: respecting human rights. Health and Human Rights Journal, 2020. 23.

14. Fineberg, N.A., et al., How to manage obsessive-compulsive disorder (O.C.D.) under COVID-19: A clinician's guide from the International College of Obsessive-Compulsive Spectrum Disorders (ICOCS) and the Obsessive-Compulsive and Related Disorders Research Network (OCRN) of the European College of Neuropsychopharmacology. Compr Psychiatry, 2020. 100: p. 152174.

15. Fazel, M., et al. Mental health interventions in schools in low-income and middle-income countries. Lancet Psychiatry, 2014. 1(5): p. 388-98.

16. Kaess, M., et al., Promoting Help-seeking using E-technology for ADolescents with mental health problems: study protocol for a randomized controlled trial within the ProHEAD Consortium. Trials, 2019. 20(1): p. 94.

17. Theodosiou, L., Children, and Young People's Mental Health 2nd Edition: Early Intervention, Ongoing Support, and Flexible Evidence-Based Care. 2020: Pavilion Publishing and Media Limited.

18. Niess, M.L., Handbook of Research on Teacher Education in the Digital Age. 2015: I.G.I. Global.

19. Garbrah, W., P. Kankkunen, and T. Välimäki, Gerontological nurse teachers' abilities and influence on students' willingness in older people nursing: A cross-sectional, correlational survey. Nurse Education Today, 2020. 90: p. 104461.

20. Valor, C., P. Antonetti, and A. Merino. The relationship between moral competences and sustainable consumption among higher education students. Journal of Cleaner Production, 2020. 248: p. 119161.

21. Maykut, C.A., Skillful Moral Leadership:: Collective Action to Foster Moral Habitability. Nurse Leader, 2019.

22. Luetz, J.M., T. Dowden, and B. Norsworthy, Reimagining Christian Education: Cultivating Transformative Approaches. 2018: Springer Singapore.

23. Griffiths, C., and Z. Tajeddin, Lessons from Good Language Teachers. 2020: Cambridge University Press.

24. Quinn, N. et al., 'People look at you differently': students' experience of mental health support within Higher Education. British Journal of Guidance \& Counselling, 2009. 37(4): p. 405-418.

25. Schulte-Korne, G., Mental Health Problems in a School Setting in Children and Adolescents. Dtsch Arztebl Int, 2016. 113(11): p. 183-90. 
26. Rith-Najarian, L.R., M.M. Boustani, and B.F. Chorpita, A systematic review of prevention programs targeting depression, anxiety, and stress in university students. Journal of Affective Disorders, 2019. 257: p. 568-584.

27. Nadeem, M., et al., impact of anxiety on the academic achievement of students having different mental abilities at the university level in Bahawalpur (Southern Punjab) Pakistan. International Online Journal of Educational Sciences, 2012. 4(3): p. 519-528.

28. Rehmani, N., Q.A. Khan, and S.S. Fatima, Stress, Anxiety and Depression in students of a private medical school in Karachi, Pakistan. Pak J Med Sci, 2018. 34(3): p. 696-701.

29. Hashmi, A.M., et al., anxiety and depression in Pakistani medical students: a multicenter study. Health Med, 2014. 8(7): p. 813-20.

30. Wang, C., et al., Immediate Psychological Responses and Associated Factors during the Initial Stage of the 2019 Coronavirus Disease (COVID-19) Epidemic among the General Population in China. International Journal of Environmental Research and Public Health, 2020. 17(5): p. 1729.

31. La, V.-P., et al., Policy Response, Social Media and Science Journalism for the Sustainability of the Public Health System Amid the COVID-19 Outbreak: The Vietnam Lessons. Sustainability, 2020. 12(7): p. 2931.

32. Dirlikov, E., Engaging Avian Influenza: The Uncertainties and Pragmatics of Pandemic Preparedness in Hong Kong-SAR. 2008, McGill University.

33. Turnbull, M., et al., Vicarious trauma, social media, and recovery in Hong Kong. Asian Journal of Psychiatry, 2020. 51: p. 102032.

34. Cao, W., et al., The psychological impact of the COVID-19 epidemic on college students in China. Psychiatry Research, 2020: p. 112934.

35. Oosterhoff, B., et al., Adolescents' Motivations to Engage in Social Distancing during the COVID-19 Pandemic: Associations with Mental and Social Health. Journal of Adolescent Health, 2020.

36. Singh, R. and R. Adhikari, Age-structured impact of social distancing on the COVID-19 epidemic in India. arXiv preprint arXiv:2003.12055, 2020.

37. van den Heuvel, L., et al., Frequency and correlates of anxiety and mood disorders among T.B.- and HIV-infected Zambians. AIDS Care, 2013. 25(12): p. 1527-1535.

38. Campbell, A.M., An increasing risk of family violence during the Covid-19 pandemic: Strengthening community collaborations to save lives. Forensic Science International: Reports, 2020. 2: p. 100089.

39. Ludvigsson, J.F., Systematic review of COVID-19 in children shows milder cases and a better prognosis than adults. Acta Paediatrica, 2020. 109(6): p. 1088-1095.

40. van Gelder, N., et al., COVID-19: Reducing the risk of infection might increase the risk of intimate partner violence. EClinicalMedicine, 2020. 21.

41. World Health Organization, W., COVID-19, and violence against women: what the health sector/system can do, April 7, 2020. 2020, World Health Organization. 
42. El Maarouf, M.D., T. Belghazi, and F. El Maarouf, COVID - 19: A Critical Ontology of the present1. Educational Philosophy and Theory, 2020: p. 1-19.

43. Mazza, M., et al., Danger in danger: Interpersonal violence during COVID-19 quarantine. Psychiatry Research, 2020. 289: p. 113046.

44. Roje Đapić, M., G. Buljan Flander, and K. Prijatelj, Children Behind Closed Doors Due to COVID-19 Isolation: Abuse, Neglect, and Domestic Violence. Archives of Psychiatry Research: An International Journal of Psychiatry and Related Sciences, 2020. 56(2): p. 181-192.

45. Mak, I.W.C., et al., Long-term psychiatric morbidities among SARS survivors. General Hospital, Psychiatry, 2009. 31(4): p. 318-326.

46. Shuja, K.H., et al., COVID-19 Pandemic and Impending Global Mental Health Implications. Psychiatr Danub, 2020. 32(1): p. 32-35.

47. Abbas, J., et al., The moderating role of social support for marital adjustment, depression, anxiety, and stress: Evidence from Pakistani working and nonworking women. J Affect Disord, 2019. 244: p. 231-238.

48. Abbas, J. et al., Tinnitus perception mediates the relationship between physiological and psychological problems among patients. Journal of Experimental Psychopathology, 2019. 10(3): p. 2043808719858559.

49. Chen, N., et al., Epidemiological and clinical characteristics of 99 cases of 2019 novel coronavirus pneumonia in Wuhan, China: a descriptive study. Lancet, 2020. 395(10223): p. 507-513.

50. Dehghani, R. and H. Kassiri, A brief review of the possible role of houseflies and cockroaches in the mechanical transmission of Coronavirus Disease 2019 (COVID-19). Archives of Clinical Infectious Diseases, 2020. 15(COVID-19).

51. Dozois, D.J.A., Beck Depression Inventory-II, in The Corsini Encyclopedia of Psychology. 2010. p. 1-2.

52. Beck, A.T., et al., An inventory for measuring clinical anxiety: psychometric properties. J Consult Clin Psychol, 1988. 56(6): p. 893-7.

53. Moss-Morris, R., et al., The Revised IIIness Perception Questionnaire (IPQ-R). Psychology \& Health, 2002. 17(1): p. 1-16.

54. Stewart-Brown, S., K. Janmohamed, and J. Parkinson, Warwick-Edinburgh Mental Wellbeing Scale: User Guide Version 1. N.H.S. Health Scotland, University of Warwick, and the University of Edinburgh. 2008.

55. Byrne, B.M., Structural Equation Modeling With AMOS: Basic Concepts, Applications, and Programming, Third Edition. 2016: Taylor \& Francis.

56. Zhou, F., et al., Clinical course and risk factors for mortality of adult inpatients with COVID-19 in Wuhan, China: a retrospective cohort study. The Lancet, 2020. 395(10229): p. 1054-1062.

57. Guo, X., et al., Meta-analysis of the prevalence of anxiety disorders in mainland China from 2000 to 2015. Sci Rep, 2016. 6(1): p. 28033. 
58. Roy, D., et al., Study of knowledge, attitude, anxiety \& perceived mental healthcare need in the Indian population during COVID-19 pandemic. Asian Journal of Psychiatry, 2020. 51: p. 102083.

59. Morgan, D., et al., Assessing the risk from emerging infections. Epidemiol Infect, 2009. 137(11): p. 1521-30.

60. Grein, T.W., et al., Rumors of disease in the global village: outbreak verification. Emerg Infect Dis, 2000. 6(2): p. 97-102.

\section{Figures}

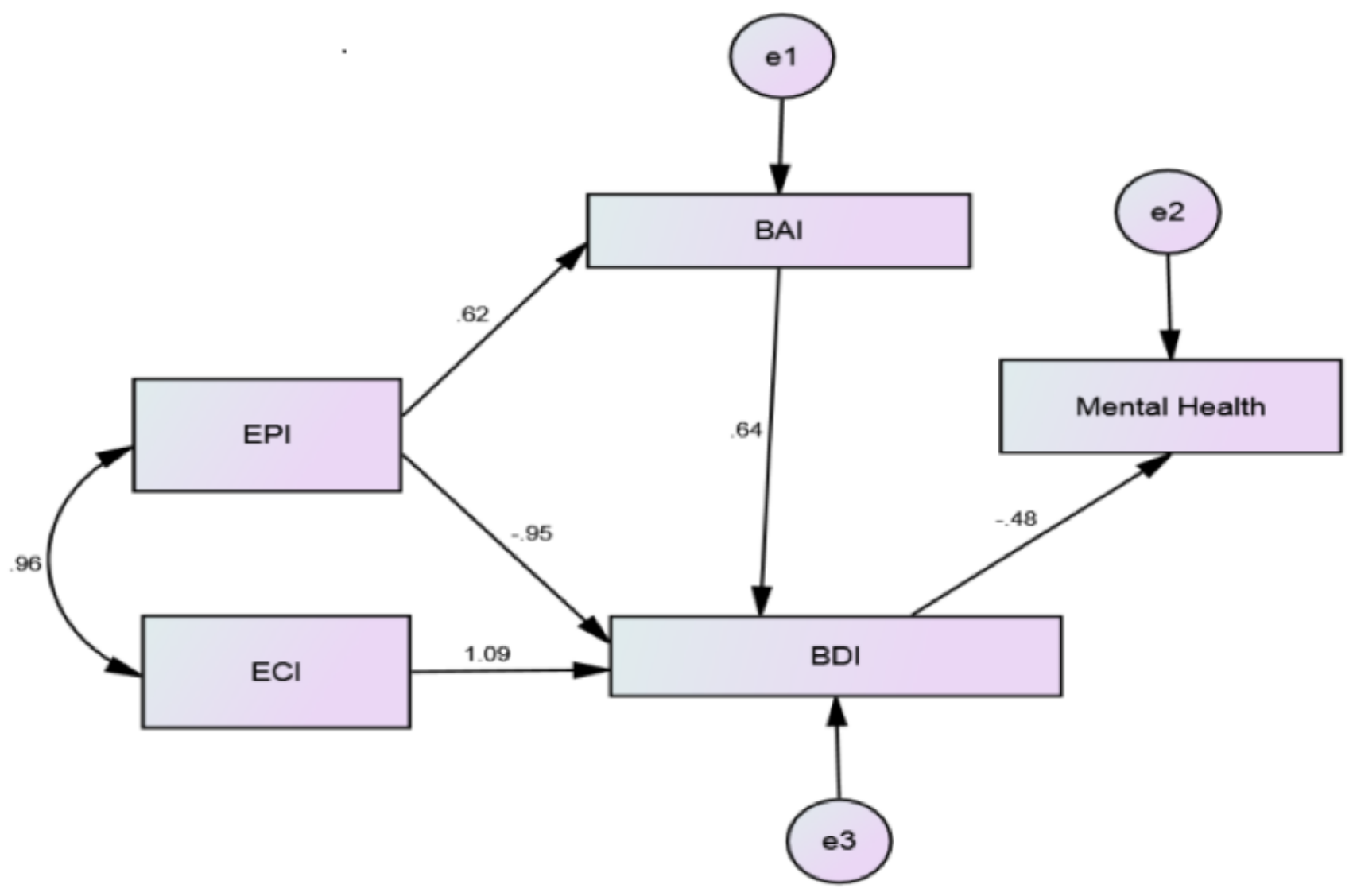

\section{Figure 1}

The mediating impact of anxiety and depression symptoms disorders between illness perception, and mental health problems in Pakistani students during the lockdown of the coronavirus outbreak $(\mathrm{N}=500)$ 